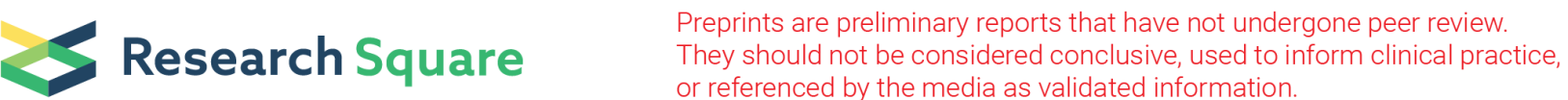

\section{Coupling structural characterization with secretomic analysis reveals mechanism of the disruption of cross-linked structure in bamboo culms by Echinodontium taxodii}

\author{
Wen Kong \\ Huazhong University of Science and Technology \\ Jialong Zhang \\ Huazhong University of Science and Technology \\ Qiuyun Xiao \\ Huazhong University of Science and Technology \\ Jiashu Liu \\ Huazhong University of Science and Technology

\section{Zhixiang Cao}

Huazhong University of Science and Technology

\section{Fuying Ma}

Huazhong University of Science and Technology

Hongbo Yu ( $\nabla$ yuhongbo@hust.edu.cn )

Huazhong University of Science and Technology https://orcid.org/0000-0002-7482-7292

\section{Research}

Keywords: Bamboo, Lignin-carbohydrate complex, Secretome, HSQC, White-rot fungi

Posted Date: December 11th, 2019

DOl: https://doi.org/10.21203/rs.2.18571/v1

License: (c) (i) This work is licensed under a Creative Commons Attribution 4.0 International License. Read Full License 


\section{Abstract}

Background: Overcoming the biomass recalcitrance is essential for efficient utilization of lignocellulosic biomass in industrial bio-refining. White-rot fungi can overcome the biomass recalcitrance and accelerate the conversion of lignocellulose to biofuels via a large number of special extracellular lignocellulolytic enzymes. Previous studies try to dissect the function of extracellular enzymes on biomass resistant cross-linked structures by secretome analysis, but the bio-alteration of cross-linked structures is ignored usually. A deeper and detailed understanding of relationship between secretome and bio-alteration of cross-linked structure in lignocellulosic biomass is still lack.

Results: As an efficient wood-decaying fungus, Echinodontium taxodii could improve the conversion efficiency of lignocellulose to biofuels. This study coupled comparative analysis of fungal secretomes and 2D HSQC NMR analysis of lignocellulose fractions, aiming to elucidate the role of extracellular enzymes from Echinodontium taxodii 2538 in the disruption of resistant cross-linked structure of bamboo culms. Carboxylesterases, alcohol oxidases and Class-Il peroxidases showed importance in the cleavage of cross-linked structures, including ester and ether linkages of lignin-carbohydrate complexes (LCCs) and inter-unit linkages of lignin, which contributed to biomass resistance removal and cellulose exposure during the early stage of fungal decay. Moreover, the rapid oxidation of $\mathrm{Ca}-\mathrm{OH}$ was found to contribute to the lignin bio-depolymerization.

Conclusions: These findings revealed the detailed mechanisms of biomass recalcitrance reduction by fungal pretreatment, and provide insight into efficient strategy of lignocellulose conversion. It will advance the development in design of enzyme cocktail for efficient lignocellulose bio-refinery.

\section{Background}

Lignocellulosic biomass is one of the most abundant feedstock for the production of renewable fuels, biomaterials, and value-added chemicals [1-3]. The efficient release of sugars from biomass in industrial bio-refining is essential but restricted by complex cross-linked structures of lignocellulose, including the rigid lignin network coating the cellulose microfibril and lignin-carbohydrate complexes (LCCs), which cross-linked lignin and polysaccharide $[4,5]$. Certain basidiomycete so-called white-rot fungi evolved effective deconstruction strategy to disrupt resistant cross-linked structures of lignocellulose for overcoming the biomass recalcitrance. These fungi can mineralize lignin preferentially, and then the exposed cellulose can be easily hydrolyzed by extracellular glycoside hydrolases. In the previous studies, a series of white-rot fungi, especially selective lignin-degrading strain, have been used to accelerate the bioconversion of lignocellulose [6]. Selective white-rot fungi degraded complex substrates synergistically depending on a large number of special extracellular lignocellulolytic enzymes [7]. Dissecting the underlying mechanisms of resistant cross-linked structures degradation by the extracellular enzymes could advance the development in design of enzyme cocktail for efficient lignocellulose biorefinery [8]. 
Secretome provides a global insight of secreted protein during fungal deconstruction of lignocellulose [9]. Many studies have revealed crucial enzymes involved in biomass degradation through comparative secretomic analysis among the different growth stages or different substrates [10,11]. For example, Cai etal found that when Lentinula edodes was cultured with woody and non-woody lignocellulosic biomass, several enzymes involved in lignin degradation were most abundant in glucose culture, while the abundance of cellulases and hemicellulases was higher in cellulose culture [12]. Kuuskeri et al. analyzed proteomes at two time points during the wood decay by Phlebia radiate, and found that the expression of specific oxidoreductases and peroxidases could be enhanced along with the release of lignin phenolic units on the early stage of decay [13]. However, due to the multi-scale changes in lignocellulosic structure and complex interaction of extracellular enzymes, identifying the key factors responsible for overcoming biomass recalcitrance was still a challenge. A deeper and detailed understanding of relationship between secretome and bio-alteration of cross-linked structure in lignocellulosic biomass is still lack.

Echinodontium taxodii, an excellent white-rot fungus able to preferentially remove resistant lignin, has been utilized in the bio-refinery of woody and herbaceous feedstock $[14,15]$. Our recent study revealed that $E$. taxodii 2538 could enhance bamboo culms saccharification through increasing the medium pore volume of biomass and improving substrate accessibility, which was mainly attributed to the selective cleavage of cross-linkages in lignin units [16]. The disruption of LCCs may also play an important role in overcoming recalcitrance of bamboo, but there is still lack of unequivocal evidence that fungus degrades LCCs. As "woody grass", bamboo culm has different lignocellulosic structure from wood or grass, which contained higher lignin content than grasses and higher syringyl/guaiacyl (S/G) unit ratio than wood [17]. Although bamboo culm is one of the most abundant forest resource in Asia, few knowledge is known about the mechanism underlying bamboo cross-linked structure degradation by selective white-rot fungus.

The aim of this study was to elucidate the role of extracellular enzymes of E. taxodii 2538 in bamboo culms cross-linked structure disruption. The secretomes of $E$. taxodii growing on bamboo for 20-days and 40-days were analyzed. Moreover, LCCs and lignin was isolated from bio-treated bamboo and characterized through two-dimensional nuclear magnetic resonance (2D NMR) spectroscopic methods. Coupled with the analysis of fungal comparative secretomes and the structural characterization of biomass, the role of fungal extracellular enzymes on the biomass deconstruction was elucidated.

\section{Results And Discussion}

\section{Dynamics of secretome of $E$. taxodii 2538 cultured in bamboo}

Lignocellulose degradation mainly relies on enzymatic reaction, especially extracellular enzymes [11]. The secretome of $E$. taxodii 2538 in bamboo biomass culture was focused on using iBAQ label-free quantification analysis. After sorted with N-terminal Sec-dependent secretion signal using SignalP 3.0, 132 secreted proteins were identified (Additional file 1: Table S1) in total. As shown in Fig. 1a, 122 
proteins showed expression at day 20. The number of extracellular proteins decreased to 81 at day 40 . According to biological functions, all secreted proteins were classified into oxidoreductases including lignolytic enzymes, glycoside hydrolases $(\mathrm{GH})$, glycosyl transferases (GT), polysaccharide lyases (PL), esterases, proteases and peptidases, and other proteins [10]. Esterases and oxidoreductases achieved the most abundance at day 20 , accounting for $33.41 \%$ and $33.38 \%$ abundance of total secretome. The glycoside hydrolases exhibited the highest diversity, with 62 and 45 proteins at day 20 and 40 , respectively (Fig. 1b). In contrast, the relative abundance of glycoside hydrolases was up to $43.41 \%$ at day 40 . The more number of extracellular enzymes and the higher diversity of secreted proteins in earlystage showed potential relationship in response to the complexity of bamboo materials, compared with later-stage [11]. The changes in protein profile of E. taxodii 2538 reflected the response of fungus to changes in composition and structures of substrates.

The contributions and fold changes of individual proteins were estimated (Fig. 1). Differences of individual protein expression at day 20 and day 40 were observed by relative abundance analysis of proteins. The fungal proteins including lignolytic enzymes, esterases and cellulases, were speculated to be important for cell wall deconstruction and analyzed at two time point.

Class-II peroxidases and laccase were believed to be responsible for the degradation of lignin [18]. Five manganese peroxidases (MnP), four lignin peroxidases ( $\mathrm{LiP}$ ) and one laccase (Lac) were identified in the secretomes of $E$. taxodii 2538. With high abundances, most of Class-II peroxidase were among top 10 expressed proteins at day 20. These results implied the importance of lignin degradation in lignocellulose conversion. As the cultivation time advanced to day 40 , the protein profile was obviously different from day 20. Peroxidase and laccase exhibited completely different secretion patterns. The expression of most peroxidases at day 20 was significantly higher than that of day 40 . The total abundance of the detected class-II peroxidase was reduced at day 40 (Fig. 1c). Only one LiP (Q53WT9) and two MnPs (Q70LM3 and A0A068PCH3) maintained high expression at day 40. Some class-Il peroxidases including three lignin peroxidases (Q3L2T9, B2BF40 and A7U4S3) and two manganese peroxidases (B2BF37 and B1B554) were not detected at day 40. On the contrary, the expression of laccase (Q53WT9) was increased greatly at day 40 . The degradation ratio of lignin was higher on the early-stage of decay with $E$. taxodii than on the later-stage (Additional file 2: Figure S1). Obviously, the expression of class-II peroxidases is consistent with the degradation of lignin. Moreover, the secretomics analysis showed that the auxiliary enzymes (aryl-alcohol oxidase/dehydrogenase, copper radical oxidase, cellobiose dehydrogenase and glyoxal oxidase) were also upregulated significantly on the early stage of fungal decay (day 20), which are a class of important enzymes to generate $\mathrm{H}_{2} \mathrm{O}_{2}$ for peroxidases [19]. These results indicated that Class-II peroxidases, instead of laccase, play an important role in the lignin degradation by $E$. taxodii 2538 . Besides enzymes involved in lignin degradation, two alcohol oxidases were also identified in oxidoreductases and showed moderate expression (Fig. 1a). Alcohol oxidases were identified in many secretome of wood rot fungi $[13,20,21]$. The role of alcohol oxidases was defined as potential hydrogen peroxide donor, supplementing the function of auxiliary enzymes in $\mathrm{H}_{2} \mathrm{O}_{2}$-supply. However, the function of alcohol oxidases on substrate in cell wall deconstruction is unclear and to be confirmed. 
It is worth noting that two carboxylesterases (A0A060SLH8 and B8PHY5) were detected. The two carboxylesterases showed very high abundance in the secretome for day 20 (Fig. 1a and 1d). The LFQ of protein A0A060SLH8 achieved the highest expression among all secreted proteins. However, the expression level of carboxylesterase was significantly reduced at 40 days. Carboxylesterases represent a large class of proteins that catalyze the hydrolysis of esters, sulfates and amides. Belonging to a subclass of carboxylesterases, ferulate esterase was thought to hydrolyze the ester bond between ferulic acids and hemicellulose, thereby destroying the connection between lignin and polysaccharides. These results meant that the two carboxylesterases might play an important role in the LCCs degradation during the early stage of decay.

The regularity of 26 cellulose degrading enzymes demonstrated differences. As shown in Fig. 1e, the expression of cellulases were limited at day 20. Relative abundances of cellulose degrading enzymes increased along with the growth of E. taxodii 2538. A GH3 protein (A0A0P3C412) and a glucanase (G3FEB8) showed the high expression among top 10 expressed proteins at day 40 (Fig. 1a).

White-rot fungal secretomes on various lignocelluloses have been investigated mostly concentrating on the model white-rot fungi [21-24]. With these data and the accumulating genomic knowledge on fungi, it is evident that each white-rot fungus expresses a unique array of CAZy and oxidoreductase enzymes and has an exquisite strategy for colonization and decay of wood.

As an efficient selective lignin-degradation white rot specie, E. taxodii 2538 was not fully investigated by omics approach before. Thus, we would like to perform an extensive and deep time point study on the secretome of fungus cultured on bamboo. The time point study in secretome analysis allowed us to observe dynamic changes in the abundances of E. taxodii expressed proteins, and to gain insight into the mechanism of cell wall deconstruction by enzymes.

Our results confirmed that the lignocellulolytic enzyme profile of $E$. taxodii is functional and composed of a variety of CAZy families including the auxiliary oxidoreductases, a set of Class-II peroxidases accompanied by $\mathrm{H}_{2} \mathrm{O}_{2}$ producing enzymes, and a selection of hydrolases, esterases and lyases. All of these enzymes were necessary for complete degradation of the polymeric lignocellulose components. The expression profiles of multiple lignin-modifying enzymes (laccase and class-II peroxidases), together with $\mathrm{H}_{2} \mathrm{O}_{2}$ producing oxidoreductases (AAO, GMCs), is more similar to the profiles of CAZymes expressed in $P$. chrysosporium $[25,26]$. Moreover, some unique features like high expression of certain class-II peroxidases and carboxylesterases but low expression of laccase at the early stage were different from many other Polyporales species [20]. In Phlebiopsis gigantea, ten class-Il peroxidases genes were identified, but none of these were detected as secreted proteins in pine wood cultures [22]. The function of peroxidases and carboxylesterases in the disruption of lignin or LCCs was still unclear. Thus, the relationship between these enzymes and bio-alteration of cross-linked structure in bamboo culm needs further confirmation via the structural characterization. 


\section{D-NMR analysis of bamboo lignin}

To gain more detailed understanding of structural alteration in the cross-linked structures of bamboo culm during E. taxodii treatment, milled wood lignin (MWL) and lignin-carbohydrate complex (LCC) samples were simultaneously isolated from raw and treated bamboo culm and characterized. The NMR spectroscopy of the isolated MWL samples, contained the lignin aliphatic region $\left(\delta_{C} / \delta_{H} 50-90 / 2.8-5.8\right)$ and aromatic region $\left(\delta_{C} / \delta_{H} 90-155 / 5.8-7.8\right)$, was shown in Fig. 2 . The chemical shifts and assignments of the main lignin structures and linkages were detailed based on the previous references (Additional file 2: Table S2) [27-29]. Table 1 summarized the relative abundance of lignin inter-unit linkages and aromatic units in the MWL samples.

$\beta-0-4$ ' aryl ethers are the most abundant inter-unit linkages in the lignin network of bamboo. The signal of $\beta-5^{\prime} / a-0-4$ ' (phenylcoumarans, B), $\beta-\beta^{\prime}$ (resinols, C), 5-5'/4-0- $\beta^{\prime}$ (dibenzodioxocin, D), a, $\beta$-diaryl ethers (E) and $\beta-1$ ' (spirodienones, F) can also be detected in NMR spectrum. Semi-quantitative analysis showed that the relative abundances of Carbon-Oxygen (C-O) and Carbon-Carbon (C-C) linkages in MWLs decreased along with fungal decay, indicating the oxidative cleavage of lignin polymer by $E$. taxodii 2538 . The strong $C-C$ bonds in lignin, such as $\beta-\beta$, a, $\beta$-diaryl ethers and $\beta-1$ ', were cleaved more rapidly than the weak $\mathrm{C}-\mathrm{O}$ bonds, leading to the great decrease of $\mathrm{C}-\mathrm{C}$ bonds ratio in the total lignin inter-unit linkage. After 40-days fungal decay, the ratio of the $\beta-0-4$ ' aryl ether bond in the total linkages increased, while the ratio of $\beta-\beta$, the main $C-C$ linkage, decreased by $65.2 \%$. After 50 -days fungal decay, the signal of all C-C linkages disappeared in NMR spectrum. Thus, the condensation degree ( $\left.\beta-\beta^{\prime} / \beta-0-4^{\prime}\right)$ of MWL was decreased along with $E$. taxodii 2538 decay. These results indicated that fungal deconstruction make the cross-linked network of the residual lignin in bamboo wood looser, thereby reducing the recalcitrance of bamboo.

It was remarkable that the percentage of Aox was increased obviously after the 20-days and 30-days fungal treatment, and the abundance of $C_{\alpha}$-oxidized units $\left(S^{\prime}\right.$ and $\left.G^{\prime}\right)$ was increased by $50.8 \%$, indicating the conversion of $\mathrm{Ca}-\mathrm{OH}$ to $\mathrm{Ca}=\mathrm{O}$ of lignin during the early stage of fungal decay with $E$. taxodii 2538 . However, the relative abundance of $\mathrm{C}_{a}$-oxidized units was decreased rapidly from 30 to 50 days. No signal of Aox or $\mathrm{C}_{a}$-oxidized units was detected in NMR spectrum of 50 -days treated samples. These results meant that $\mathrm{Ca}=0$ could be intermediate product of lignin during the lignin depolymerization with $E$. taxodii 2538. It is well known that the lignin with the $\beta-0-4$-ketone structure is more susceptible to be disrupted than the lignin with the $\beta-0-4$-alcohol structure. For example, lignin valorization processes usually improved the efficiency of lignin depolymerization through prior $\mathrm{Ca}-\mathrm{OH}$ oxidation [30]. The $\mathrm{Ca}-\mathrm{OH}$ oxidation by $\mathrm{NAD}^{+}$-dependent Ca-dehydrogenases (LigD) is necessary for the lignin metabolism of bacterium Sphingobium sp. SYK-6 [31]. Therefore, E. taxodii 2538 could enhance the cleavage of the inter-unit linkages of bamboo lignin through the $\mathrm{Ca}-\mathrm{OH}$ oxidation of lignin side chain during the early stage of the fungal decay. 
The aromatic region in spectra showed the backbone of bamboo lignin was composed of syringyl unit $(\mathrm{S})$, guaiacyl unit $(\mathrm{G})$, p-hydroxyphenyl unit $(\mathrm{H})$, p-coumarates (PCA), ferulates (FA) and tricin (Fig. 2). The decrease of $S / G$ ratios from 1.47 to 1.23 was observed along with fungal decay, confirming preferential degradation of the S-units by E. taxodii 2538. It could be explained by the fact that S-units with less redox potential, closer location to polysaccharides, lower condensation degree, is easier and more necessary to be degraded in the fungi lifespan. In HSQC spectrum, signals from $F A\left(\mathrm{C}_{2}-\mathrm{H}_{2}\right.$ and $\left.\mathrm{C}_{6}-\mathrm{H}_{6}\right)$ were observed at $\delta \mathrm{C} / \delta \mathrm{H} 111.0 / 7.32$ and $123.2 / 7.15 \mathrm{ppm}$. The percent of $\mathrm{FA}(\mathrm{FA} / \mathrm{S}+\mathrm{G}+\mathrm{H})$ decreased rapidly from $2.17 \%$ to $0.36 \%$, in MWLs of bamboo. FA can bridge lignin and hemicellulose through ester linkages and phenol coupling reactions, forming a cross-linked LCC structure [32,33]. The previous studies also found the removal of FA unit in lignin during the white-rot fungal decay, which indicated that LCC linkage bridged by FA may be cleaved by white-rot fungus [34]. However, FA-linked structure is one of LCC structures in lignocellulose. The direct structural evidence of LCCs biodegradation with white-rot fungus to date is still lack.

\section{D-NMR analysis of bamboo LCCs}

To confirm LCCs biodegradation by white-rot fungus, LCC samples isolated from raw and treated bamboo culm were analyzed by 2D NMR. Different from other LCC isolation, we applied a classic isolation method and obtained the Björkman LCC of bamboo samples. More carbohydrates exist in Björkman LCC, which composed with about 30\% lignin and 70\% carbohydrates (Additional file 2: Table S3). As a typical complex of lignin and carbohydrate, the isolated Björkman LCC samples were suitable for exploration of LCC linkages. HSQC spectra of LCCs provided important structural information and were shown in Fig. 3 and 4. Currently, most studies on LCC structure focus on the woody plant [5]. Generally, the main types of LCC linkages in wood are believed to be phenyl glycoside bonds, esters and benzyl ethers. Bamboo as "woody grass" has different structure from herbaceous and woody plants, but studies on the structure and degradation of bamboo LCC are still limited. Especially for bamboo Björkman LCC, there was no report about its isolation and structural analysis. LCC linkages were identified and showed in Fig. 4. Table 2 summarized the relative abundance of major structures in the LCCs of raw and treated bamboo samples.

Different from other woody LCC, FA motif is an important units in LCC, with high relative abundance $(\mathrm{FA} /(\mathrm{S}+\mathrm{G}+\mathrm{H}))$ of $39.4 \%$ in raw sample. As mentioned above, ferulate can be esterified to the xylan in LCCs. Several signals of esterified FA were observed in 116.5/6.33 ppm [29]. The signals vanished in LCCs after 20-days decay. Fungal cleavage of FA-ester linkages resulted in a rapid decline in the relative abundance of $F A$ in $L C C s$, and $F A /(S+G+H)$ was decreased by $66.5 \%$ and $84.8 \%$ in 20 -days and 50 -days treated bamboo LCCs compared to that in the raw bamboo LCCs.

In the study, the signals of $y$-esters were observed in the area of 65-62/4.0-4.5 ppm. Fungal treatment with E. taxodii 2538 led to the decrease of $y$-ester linkages in isolated LCC samples along with fungal decay. The abundance of $\gamma$-ester linkages in the 50 -days treated bamboo LCC was decreased $74.9 \%$, compared 
to that in the raw bamboo LCCs. Normally, $p$-coumaric acid $(p C A)$ and acetic acid (Ac) are acylated at $C-y$ of lignin side chain in grass lignin, which influence the calculation of $y$-ester linkages in LCC [35]. The decrease of $y$-ester linkage cannot truly reflect the disruption of $y$-ester linkages linked with carbohydrates in LCC. 4-0-methyl-a-D-glucuronic acid units was reported to be linked to lignin by benzyl ester bonds [5]. The anomeric correlations from esterified 4-0-methyl-a-D-glucuronic acid units (GICAE) was clearly observed at $\delta \mathrm{C} / \delta \mathrm{H} 97.2 / 5.18$. After fungal treatment, the relative abundance of GlcAE unit was decreased by $86.7 \%$. The decrease of GlcAE units by E. taxodii 2538 further demonstrated the cleavage of $\mathrm{y}$-ester linkages in bamboo LCCs during biomass deconstruction. It was worth noting that the y-ester linkages in LCCs were cleaved by E. taxodii 2538 more rapidly during the early stages of treatment. After 20-days fungal treatment, the abundance of GICAE was decreased by $66.7 \%$.

Several signals of carbohydrates C-1 in phenyl glycoside linkages were detected at 104-99/4.8-5.2 ppm. These signals indicate different types of carbohydrates in phenyl glycoside linkages. The signals of $\beta-D-$ xylopyranoside units $\left(X_{1}\right)$ were observed at $103.2 / 4.20 \mathrm{ppm}$, whereas the correlations of $\beta$-Dglucopyranoside units $\left(\mathrm{Glc}_{1}\right)$ might be overlapped in this region. The signal from the reducing end of (14)-a-D-xylopyranoside $\left(\mathrm{aX}_{1}\right)$ was found at 92.2/4.88 ppm. The cross-signals of PhGlc2 and PhGlc3 were detected at 100.6/4.65, and 101.5/4.79 ppm, respectively. The abundance of phenyl glycoside $\left(\mathrm{PhGlc}_{2}\right.$ and $\mathrm{PhGl}_{3}$ ) declined from 0.017 to 0.01 and from 0.008 to 0.004 , respectively.

The amounts of benzyl ether LCC linkages were quantified by the signal of $\mathrm{CH}-\mathrm{a}$ in these structures. There were two types of benzyl ether LCC structures: (a) C1-linkages between the a-position of lignin and primary $\mathrm{OH}$ groups of carbohydrates (at C-6 of Glc, Gal and Man and C-5 of Ara) and (b) C2-linkages between the a-position of lignin and secondary $\mathrm{OH}$ groups of carbohydrates, mainly of lignin-xylan type. The signals of benzyl ether C2-linkages giving a cross-peak at 80-81/5.1-4.9 ppm in LCCs disappeared rapidly at day 20 (Fig. 3). The signals of C1-linkages which giving a cross-peak at 80-81/4.5-4.7 ppm were not detected.

In summary, 2D-NMR analysis of the isolated LCC samples confirmed that the resistant cross-linked structures of LCCs, including lignin-ferulic acid-ester-hemicellulose linkage, phenyl glycoside bonds, esters and benzyl ethers, could be cleaved by E. taxodii 2538 , especially at the early stages.

\section{Coupled analysis of cross-linked structures degradation and enzymes expression}

In the bamboo cell wall, ferulic acid is an important bridge unit, linked to lignin and hemicellulose simultaneously, forming lignin-ferulic acid- ester-hemicellulose linkages. The percentage of FA (based on $\mathrm{S}+\mathrm{G}+\mathrm{H}$ ) in raw bamboo LCCs was $39.4 \%$ much higher than FA in MWL. It shows the importance of FA in LCC. Along with fungal decay, 75.5\% FA unit and most FA ester in LCC declined in 20 days. The fact suggested that disruption of ferulic acid ester bond probably occurred at early stage. Normally, ferulic acid esterase, belong to carboxylesterase with carboxylic ester hydrolase activities, is responsible for 
ferulic acid ester bond disruption [36]. While there was no specific ferulic acid esterase detected in the secretome, two important carboxylesterase were detected and maybe involved in the disruption of ferulic acid ester bond. They were expressed with highest abundance on day 20 and showed moderate expression on day 40 , fitting well with the disruption profiles of FA and FA-ester during the fungal treatment.

Most of lignin fragments in plant biomass are covalently linked to hemicellulose coating cellulose microfiber [32,37]. The cross-linked structure of lignin and polysaccharides is partly responsible for the lignocellulose recalcitrance. Fungal esterase with ability to cleave ester bonds has been wildly used to improve saccharification of lignocellulose [38]. Recent studies speculated that the breakdown of LCCs during fungal treatment may play an important role in improving biomass digestibility $[34,38,39]$. However, there is still lack of the unequivocal proof that fungus degrades LCCs. In this study, LCCs was isolated from fungus-treated bamboo and characterized by 2D NMR spectroscopy. Based on structural analysis, all the main linkages of LCC in bamboo were disrupted rapidly in 20 days pretreatment. It might be the explanation for reduced biomass resistance at early stage. These findings firstly provided the direct evidences that white-rot fungus degrades the linkages in LCCs. The disruption of LCC linkages might be attributed to the extracellular carboxylesterase. These esterases may play a role in the cleavage of ester linkages of cross-linkages between hemicellulose and lignin.

A set of proteins related to lignin degradation had been overproduced, especially at early stage. The high expression of Class-II peroxidases at early stage showed their key roles in the cleavage of inter-units of lignin. As observed in MWL-20, $\mathrm{Ca}-\mathrm{OH}$ of $\mathrm{S}$ and $\mathrm{G}$ units was oxidized to $\mathrm{Ca}=\mathrm{O}$ by $\mathrm{E}$. taxodii 2538. Laccase was considered to be responsible for $S$ and $G$ units oxidation and degradation [40,41]. Although laccase was one of top-15 expressed proteins, laccase mainly expressed at day 40 . It was not consistent with the rapid $\mathrm{Ca}-\mathrm{OH}$ oxidation and lignin degradation during early dacay. Overproduced on the early stage, alcohol oxidases which catalyze the oxidation of alcohols to the aldehyde compounds with a concomitant release of hydrogen peroxide, may be not only as hydrogen peroxide donor, but also play a role in oxidation of $\mathrm{Ca}-\mathrm{OH}$ in $\mathrm{S}$ and $\mathrm{G}$ units. The oxidation is proved to reduce the strength of other bonds like $\beta-0-4$, accelerating complex lignin network deconstruction. The role of alcohol oxidase in lignin degradation may be underestimated before.

Lignin degradation along with LCC linkages disruption, increased the access of polysaccharides in bamboo, especially cellulose. It fits well with the white-rot decay mechanism in which lignin depolymerization precedes cellulose degradation. E. taxodii 2538 displayed increased expression of a set of cellulases at day 40 remarkably, to release sugar and supply energy for cells. The expression of three main cellulytic proteins (A0A0C3P412, G3FEB8 and G3FEB8) were among top-10 at day 40, which illustrated that the main target of the fungus turned to cellulose from lignin.

\section{Conclusions}


The role of extracellular enzymes of E. taxodii 2538 in the disruption of cross-linked structure of bamboo was illuminated through coupling secretome analysis and structure characterization. The expression of carboxylesterases, alcohol oxidases and Class-II peroxidases were related to the deconstruction of LCC and lignin. The resistant cross-linked structures, including lignin-ether-ferulic acid-ester-hemicellulose linkage, phenyl glycoside, esters and benzyl ethers linkages of LCC and inter-unit linkage of lignin, were cleaved at early stage. The rapid oxidation of $\mathrm{Ca}-\mathrm{OH}$ at early stage may contribute to the lignin biodepolymerization. These findings will advance the development in enzyme cocktail design for efficient lignocellulose biorefinery.

\section{Methods}

\section{Microorganism and cultivation}

White-rot fungus E. taxodii 2538 was obtained from Shennongjia Scenic Area in Hubei of China, isolated and identified by the authors in Key Laboratory of Molecular biophysics of MOE, Huazhong University of Science \& Technology. $6 \mathrm{~g}$ dried bamboo materials with fine particle size (20-80 mesh) was mixed with $13.5 \mathrm{ml}$ distilled water in $250 \mathrm{ml}$ Erlenmeyer flasks. After sterilized at $121^{\circ} \mathrm{C}$ for 30 minutes, each flask was inoculated with $10 \mathrm{ml}$ mycelium suspension and cultured at $28^{\circ} \mathrm{C}$.

\section{Secreted proteins isolation and analysis}

After 20-days and 40-days cultivation, secreted proteins were isolated. After brought into $0.05 \mathrm{~mol} / \mathrm{L}$ citrate-phosphate buffer ( $\mathrm{pH} 7.0$ ), extracellular proteins were separated by sodium dodecyl sulfate polyacrylamide gel electrophoresis (SDS-PAGE). $5 \mu \mathrm{g}$ Sequencing grade modified Trypsin in $40 \mu \mathrm{L}$ dissolution buffer was used to digest the supernatant at $37^{\circ} \mathrm{C}$. The tryptic peptides of the supernatant were analyzed by Q-exactive mass spectrometer (LTQFT Ultra mass spectrometer, Thermo) coupling a capillary high performance liquid chromatography (easy Nlc1000, Thermo) same as reference [42].

The iBAQ label-free quantification (LFQ) analysis of liquid chromatography-tandem mass spectrometry (LC-MS/MS) raw data in Maxquant software (version 1.3.0.5) was carried out [43]. The proteins were identified according to the database of JGI with default parameters. The accurate relative abundance of all identified proteins was obtained from the iBAQ intensities. After sorted with $\mathrm{N}$-terminal Sec-dependent secretion signal using SignalP 3.0, all secreted proteins were analyzed quantified.

\section{Isolation and HSQC analysis of MWL and LCC}

The milled wood lignin (MWL) and lignin-carbohydrate complex (LCC) were isolation from raw and fungal treated bamboo (Additional file 2: Figure S2). The MWL and LCC samples from raw and treated bamboo culms were analyzed with heteronuclear single quantum coherence spectroscopy (HSQC). The isolated lignin (100 mg) was suspended in $0.75 \mathrm{ml}$ of DMSO-d6 in the NMR tube. The experiments has been 
explained in detail in previous paper [16]. The brief parameters are: ${ }^{1} \mathrm{H}$ widths of $5,000 \mathrm{~Hz}$ in 2048 points with a recycle delay of $1.75 \mathrm{~s} ;{ }^{13} \mathrm{C}$ spectral widths of $25,000 \mathrm{~Hz}$. Cetral DMSO peak $\left(\delta_{H} / \delta_{C} 2.50 / 39.5\right)$ was used for reference. Correlation peaks of MWLs and LCCs were assigned according to the previous report (Additional file 2: Table S2 and S4). A semi-quantitative analysis of the integrals of the HSQC correlation peaks was performed using MestReNova (version 6.0.1).

\section{Supplementary Information}

Additional file 1: Table S1. Detailed information of all secreted proteins identified in secretomes.

Additional file 2: Figure S1. The degradation ratio of lignin, cellulose and hemicellulose during fungal treatment of bamboo samples. Figure $\mathbf{S 2}$. The main isolation procedures of MWLs and LCCs from raw and treated bamboo. Table S2. The assignments of ${ }^{13} \mathrm{C}^{-1} \mathrm{H}$ peaks in HSQC spectrum from the isolated MWLs. Table S3. Sugar and Lignin Analysis of MWL and LCC Preparations. Table S4. The assignments of ${ }^{13} \mathrm{C}^{-1} \mathrm{H}$ peaks in HSQC spectrum from the isolated LCCs

\section{Abbreviations}

HSQC: heteronuclear single quantum coherence spectroscopy; 2D NMR: two-dimensional nuclear magnetic resonance; LCC: lignin-carbohydrate complexe; GH: glycoside hydrolase; GT: glycosyl transferase; PL: polysaccharide lyase; CE: carbohydrate esterase; MnP: manganese peroxidase; LiP: lignin peroxidase; Lac: laccase; AAO: aryl-alcohol oxidase; GMC oxidoreductase: glucose-methanol-choline oxidoreductase; CAZymes: Carbohydrate-Active Enzymes; MWL: milled wood lignin; LigD: lignin dehydrogenase; S: syringyl; G: guaiacyl; $\mathrm{H}$ : $p$-hydroxyphenyl; PCA: $p$-coumarates; FA: ferulates; $p$ CA: $p$ coumaric acid; Ac: acetic acid; GIcAE: esterified 4-0-methyl-a-D-glucuronic acid units; X1: $\beta$-Dxylopyranoside; Glc $\mathbf{c}_{1}$ : $\beta$-D-glucopyranoside; aX1: (1-4)-a-D-xylopyranoside; PhGlc: phenyl glycoside; Glc: glucose; Gal: galactose; Man: mannose; Ara: arabinose; SDS-PAGE: sodium dodecyl sulfate polyacrylamide gel electrophoresis; LFQ: label-free quantification; LC-MS/MS: liquid chromatographytandem mass spectrometry

\section{Declarations}

\section{Ethics approval and consent to participate}

Not applicable.

\section{Consent for publication}

Not applicable.

\section{Availability of data and materials}


All data generated or analyzed during this study are included in this published article and its additional information files.

\section{Competing interests}

The authors declare that they have no competing interests.

\section{Fundings}

This work was supported by National Key Research and Development Program of China (No.2017YF0400301), the National Basic Research Program of China (No.2014CB138301), the National Natural Science Foundation of China (No.31570577).

\section{Authors' contributions}

JZ, HY and WK drafted the manuscript. WK design the study and performed fungal culture. JZ performed secretome and structural analysis. QX assisted in secretome analysis. JL, ZC and FM reviewed the manuscript. All authors read and approved the final manuscript.

\section{Acknowledgements}

The authors also thank the work of Analytical and Testing Center in Huazhong University of Science and Technology for 2D HSQC NMR analysis.

\section{References}

1. Liao JC, Mi L, Pontrelli S, Luo S. Fuelling the future: microbial engineering for the production of sustainable biofuels. Nat Rev Micro. 2016;14(5):288-304.

2. Linger JG, Vardon DR, Guarnieri MT, Karp EM, Hunsinger GB, Franden MA, Johnson CW, Chupka G, Strathmann TJ, Pienkos PT, et al. Lignin valorization through integrated biological funneling and chemical catalysis. Proc Natl Acad Sci U S A. 2014;111(33):12013-12018.

3. Davison BH, Ragauskas AJ, Templer R, Tschaplinski TJ, Mielenz JR. Measuring the efficiency of biomass energy. Science. 2006;312(5781):1744-1745.

4. Lawoko M, Henriksson G, Gellerstedt G. Structural differences between the lignin-carbohydrate complexes present in wood and in chemical pulps. Biomacromolecules. 2005;6(6):3467-3473.

5. Du X, Pérez-Boada M, Fernández C, Rencoret J, del Río JC, Jiménez-Barbero J, Li J, Gutiérrez A, Martínez AT. Analysis of lignin-carbohydrate and lignin-lignin linkages after hydrolase treatment of xylan-lignin, glucomannan-lignin and glucan-lignin complexes from spruce wood. Planta. 2014;239(5):1079-1090.

6. Wagner AO, Lackner N, Mutschlechner M, Prem EM, Markt R, Illmer P. Biological pretreatment strategies for second-generation lignocellulosic resources to enhance biogas production. Energies. 2018;11(7). 
7. Armstrong Z, Mewis K, Strachan C, Hallam SJ. Biocatalysts for biomass deconstruction from environmental genomics. Curr Opin Chem Biol. 2015;29:18-25.

8. Silva GGD, Couturier M, Berrin J-G, Buléon A, Rouau X. Effects of grinding processes on enzymatic degradation of wheat straw. Bioresour Technol. 2012;103(1):192-200.

9. Adav SS, Sze SK. Fungal secretome for biorefinery: recent advances in proteomic technology. Mass Spectrom Lett. 2013;4(1):1-9.

10. Fernández-Fueyo E, Ruiz-Dueñas FJ, López-Lucendo MF, Pérez-Boada M, Rencoret $J$, Gutiérrez A, Pisabarro AG, Ramírez L, Martínez AT. A secretomic view of woody and nonwoody lignocellulose degradation by Pleurotus ostreatus. Biotechnol Biofuels. 2016;9(1):49.

11. Rytioja J, Hilden K, Di Falco M, Zhou M, Aguilar-Pontes MV, Sietio OM, Tsang A, de Vries RP, Makela MR. The molecular response of the white-rot fungus Dichomitus squalens to wood and non-woody biomass as examined by transcriptome and exoproteome analyses. Environ Microbiol. 2017;19(3):1237-1250.

12. Cai Y, Gong Y, Liu W, Hu Y, Chen L, Yan L, Zhou Y, Bian Y. Comparative secretomic analysis of lignocellulose degradation by Lentinula edodes grown on microcrystalline cellulose, lignosulfonate and glucose. J Proteomics. 2017;163:92-101.

13. Kuuskeri J, Häkkinen M, Laine P, Smolander O-P, Tamene F, Miettinen S, Nousiainen P, Kemell M, Auvinen $\mathrm{P}$, Lundell T. Time-scale dynamics of proteome and transcriptome of the white-rot fungus Phlebia radiata: growth on spruce wood and decay effect on lignocellulose. Biotechnol Biofuels. 2016;9(1):192.

14. Yu H, Guo G, Zhang X, Yan K, Xu C. The effect of biological pretreatment with the selective white-rot fungus Echinodontium taxodii on enzymatic hydrolysis of softwoods and hardwoods. Bioresour Technol. 2009;100(21):5170-5175.

15. Zhang $X, Y u H$, Huang $H$, Liu Y. Evaluation of biological pretreatment with white rot fungi for the enzymatic hydrolysis of bamboo culms. Int Biodeterior Biodegrad. 2007;60(3):159-164.

16. Ma F, Huang X, Ke M, Shi Q, Chen Q, Shi C, Zhang J, Zhang X, Yu H. Role of selective fungal delignification in overcoming the saccharification recalcitrance of bambooculms. ACS Sustainable Chem Eng. 2017;5(10):8884-8894.

17. Wen J-L, Sun S-L, Xue B-L, Sun R-C. Structural elucidation of inhomogeneous lignins from bamboo. Int J Biol Macromol. 2015;77:250-259.

18. Salvachua D, Katahira R, Cleveland NS, Khanna P, Resch MG, Black BA, Purvine So, Zink EM, Prieto A, Martinez $\mathrm{MJ}$, et al. Lignin depolymerization by fungal secretomes and a microbial sink. Green Chem. 2016:6046-6062.

19. Mathieu Y, Piumi F, Valli R, Aramburu JC, Ferreira P, Faulds CB, Record E. Activities of secreted aryl alcohol quinone oxidoreductases from Pycnoporus cinnabarinus provide insights into fungal degradation of plant biomass. Appl Environ Microbiol. 2016;82(8):2411-2423.

20. Couturier M, Navarro D, Chevret D, Henrissat B, Piumi F, Ruiz-Dueñas FJ, Martinez AT, Grigoriev IV, Riley R, Lipzen A, et al. Enhanced degradation of softwood versus hardwood by the white-rot fungus 
Pycnoporus coccineus. Biotechnol Biofuels. 2015;8:216.

21. Vanden Wymelenberg A, Gaskell J, Mozuch M, BonDurant SS, Sabat G, Ralph J, Skyba O, Mansfield SD, Blanchette RA, Grigoriev IV, et al. Significant alteration of gene expression in wood decay fungi Postia placenta and Phanerochaete chrysosporium by plant species. Appl Environ Microbiol. 2011;77(13):4499-4507.

22. Hori C, Ishida T, Igarashi K, Samejima M, Suzuki H, Master E, Ferreira P, Ruiz-Duenas FJ, Held B, Canessa P, et al. Analysis of the Phlebiopsis gigantea genome, transcriptome and secretome provides insight into its pioneer colonization strategies of wood. PLoS Genet. 2014;10(12):20.

23. Mahajan S, Master ER, Biotechnology. Proteomic characterization of lignocellulose-degrading enzymes secreted by Phanerochaete carnosa grown on spruce and microcrystalline cellulose. Appl Microbiol Biotechnol. 2010;86(6):1903-1914.

24. Salvachúa D, Martínez AT, Tien M, López-Lucendo MF, García F, de los Ríos V, Martínez MJ, Prieto A. Differential proteomic analysis of the secretome of Irpex lacteus and other white-rot fungi during wheat straw pretreatment. Biotechnol Biofuels. 2013;6(1):115.

25. Korripally P, Hunt CG, Houtman CJ, Jones DC, Kitin PJ, Cullen D, Hammel KE. Regulation of gene expression during the onset of ligninolytic oxidation by Phanerochaete chrysosporium on spruce wood. Appl Environ Microbiol. 2015;81(22):7802-7812.

26. Vanden Wymelenberg A, Gaskell J, Mozuch M, Kersten P, Sabat G, Martinez D, Cullen D. Transcriptome and secretome analyses of Phanerochaete chrysosporium reveal complex patterns of gene expression. Appl Environ Microbiol. 2009;75(12):4058-4068.

27. del Rio JC, Rencoret J, Prinsen P, Martinez AT, Ralph J, Gutierrez A. Structural characterization of wheat straw lignin as revealed by analytical pyrolysis, 2D-NMR, and reductive cleavage methods. J Agric Food Chem. 2012;60(23):5922-5935.

28. Wen J-L, Xue B-L, Xu F, Sun R-CJBR. Unveiling the structural heterogeneity of bamboo lignin by In situ HSQC NMR technique. BioEnergy Res. 2012;5(4):886-903.

29. Wen J-L, Xue B-L, Xu F, Sun R-C, Pinkert A. Unmasking the structural features and property of lignin from bamboo. Ind Crops Prod. 2013;42:332-343.

30. Song Y, Motagamwala AH, Karlen SD, Dumesic JA, Ralph J, Mobley JK, Crocker M. A comparative study of secondary depolymerization methods on oxidized lignins. Green Chem. 2019;21(14):39403947.

31. Husarcíková J, Voß H, Domínguez de María P, Schallmey A, Biotechnology. Microbial $\beta$-etherases and glutathione lyases for lignin valorisation in biorefineries: current state and future perspectives. Appl Microbiol Biotechnol. 2018;102(13):5391-5401.

32. Grabber JH. How do lignin composition, structure, and cross-linking affect degradability? a review of cell wall model studies. Crop Sci. 2005;45(3):820-831.

33. Tarasov D, Leitch M, Fatehi P. Lignin-carbohydrate complexes: properties, applications, analyses, and methods of extraction: a review. Biotechnol Biofuels. 2018;11(1):269. 
34. Zeng J, Singh D, Gao D, Chen S. Effects of lignin modification on wheat straw cell wall deconstruction by Phanerochaete chrysosporium. Biotechnol Biofuels. 2014;7(1):161.

35. del Rio JC, Rencoret J, Marques G, Gutierrez A, Ibarra D, Santos JI, Jimenez-Barbero J, Zhang L, Martinez AT. Highly acylated (acetylated and/or p-coumaroylated) native lignins from diverse herbaceous plants. J Agric Food Chem. 2008;56(20):9525-9534.

36. Buanafina MMdO, Langdon T, Hauck B, Dalton S, Timms-Taravella E, Morris P. Targeting expression of a fungal ferulic acid esterase to the apoplast, endoplasmic reticulum or golgi can disrupt feruloylation of the growing cell wall and increase the biodegradability of tall fescue Festuca arundinacea. Plant Biotechnol J. 2010;8(3):316-331.

37. Meng X, Ragauskas AJ. Recent advances in understanding the role of cellulose accessibility in enzymatic hydrolysis of lignocellulosic substrates. Curr Opin Biotechnol. 2014;27(0):150-158.

38. d'Errico C, Börjesson J, Ding H, Krogh KBRM, Spodsberg N, Madsen R, Monrad RN. Improved biomass degradation using fungal glucuronoyl-esterases-hydrolysis of natural corn fiber substrate. $\mathrm{J}$ Biotechnol. 2016;219:117-123.

39. Selig MJ, Knoshaug EP, Adney WS, Himmel ME, Decker SR. Synergistic enhancement of cellobiohydrolase performance on pretreated corn stover by addition of xylanase and esterase activities. Bioresour Technol. 2008;99(11):4997-5005.

40. Longe LF, Couvreur J, Grandchamp ML, Garnier G, Allais F, Saito K. Importance of mediators for lignin degradation by fungal laccase. ACS Sustainable Chem Eng. 2018;6(8):10097-10107.

41. Rico A, Rencoret J, del Rio JC, Martinez AT, Gutierrez A. In-depth 2D NMR study of lignin modification during pretreatment of eucalyptus wood with laccase and mediators. BioEnergy Res. 2015;8(1):211230.

42. Xiao Q, Yu H, Zhang J, Li F, Li C, Zhang X, Ma F. The potential of cottonseed hull as biorefinery substrate after biopretreatment by Pleurotus ostreatus and the mechanism analysis based on comparative proteomics. Ind Crops Prod. 2019;130:151-161.

43. Cox J, Hein MY, Luber CA, Paron I, Nagaraj N, Mann M. Accurate proteome-wide label-free quantification by delayed normalization and maximal peptide ratio extraction, termed MaxLFQ. Mol Cell Proteomics. 2014;13(9):2513-2526.

\section{Tables}

Table 1. Structural Characteristics in the HSQC Spectra of the isolated MWL samples. 


\begin{tabular}{|c|c|c|c|c|c|}
\hline & & & MWL & & \\
\hline & $O d$ & $20 d$ & $30 \mathrm{~d}$ & $40 d$ & $50 d$ \\
\hline lignin aromatic units ${ }^{a}$ & & & & & \\
\hline$S$ & $\begin{array}{c}0.202 \\
(56.5 \%)\end{array}$ & $\begin{array}{c}0.178 \\
(54.5 \%)\end{array}$ & $\begin{array}{c}0.167 \\
(53.2 \%)\end{array}$ & $\begin{array}{c}0.107 \\
(52.8 \%)\end{array}$ & $\begin{array}{c}0.099 \\
(52.7 \%)\end{array}$ \\
\hline G & $\begin{array}{c}0.068 \\
(38.4 \%)\end{array}$ & $\begin{array}{c}0.066 \\
(40.6 \%)\end{array}$ & $\begin{array}{c}0.066 \\
(41.8 \%)\end{array}$ & $\begin{array}{c}0.043 \\
(42.4 \%)\end{array}$ & 0.04 (42.7\%) \\
\hline $\mathrm{H}$ & $\begin{array}{c}0.019 \\
(5.19 \%)\end{array}$ & $\begin{array}{c}0.016 \\
(4.94 \%)\end{array}$ & $\begin{array}{c}0.016 \\
(5.02 \%)\end{array}$ & $\begin{array}{c}0.001 \\
(4.89 \%)\end{array}$ & $\begin{array}{c}0.009 \\
(4.55 \%)\end{array}$ \\
\hline$S / G$ & 1.47 & 1.34 & 1.27 & 1.25 & 1.23 \\
\hline$S^{\prime}+G^{\prime}(\%)$ & $6.54 \%$ & $7.83 \%$ & $9.86 \%$ & $3.95 \%$ & $0.00 \%$ \\
\hline FA & 0.003 & 0.002 & 0.002 & 0.001 & ND \\
\hline $\mathrm{FA} /(\mathrm{S}+\mathrm{G}+\mathrm{H})$ & $2.17 \%$ & $1.81 \%$ & $1.62 \%$ & $1.25 \%$ & $0.36 \%$ \\
\hline lignin interunit linkages ${ }^{\mathbf{b}}$ & & & & & \\
\hline$\beta-0-4^{\prime}$ aryl ethers $\left(A / A^{\prime}\right)$ & $\begin{array}{c}0.211 \\
(59.8 \%)\end{array}$ & $0.2(65.8 \%)$ & $\begin{array}{c}0.198 \\
(68.9 \%)\end{array}$ & $\begin{array}{c}0.149 \\
(82.9 \%)\end{array}$ & $\begin{array}{c}0.141 \\
(100.0 \%)\end{array}$ \\
\hline $\begin{array}{l}\text { a-oxidized } \beta-0-4 \text { ' aryl ethers } \\
\text { (Aox) }\end{array}$ & $0.01(2.7 \%)$ & $0.01(3.3 \%)$ & $\begin{array}{l}0.013 \\
(4.4 \%)\end{array}$ & $\begin{array}{l}0.004 \\
(2.0 \%)\end{array}$ & ND \\
\hline $\begin{array}{l}\beta-5^{\prime} / a-0-4^{\prime} \\
\text { (phenylcoumarans, B) }\end{array}$ & $\begin{array}{l}0.027 \\
(7.6 \%)\end{array}$ & $\begin{array}{l}0.023 \\
(7.5 \%)\end{array}$ & $\begin{array}{l}0.022 \\
(7.5 \%)\end{array}$ & $\begin{array}{l}0.012 \\
(6.8 \%)\end{array}$ & ND \\
\hline$\beta-\beta^{\prime}($ resinols, $C)$ & $\begin{array}{c}0.063 \\
(17.8 \%)\end{array}$ & $\begin{array}{c}0.043 \\
(14.0 \%)\end{array}$ & $\begin{array}{c}0.034 \\
(11.7 \%)\end{array}$ & $\begin{array}{l}0.011 \\
(6.2 \%)\end{array}$ & ND \\
\hline $\begin{array}{l}5-5^{\prime} \\
\text { (dibenzodioxocins D) }\end{array}$ & $\begin{array}{l}0.014 \\
(4.0 \%)\end{array}$ & $\begin{array}{l}0.009 \\
(3.1 \%)\end{array}$ & $\begin{array}{l}0.006 \\
(2.1 \%)\end{array}$ & ND & ND \\
\hline $\begin{array}{l}a-0-4^{\prime} / \beta-0-4^{\prime} \\
(a, \beta \text {-diaryl ethers } E)\end{array}$ & $\begin{array}{l}0.012 \\
(3.5 \%)\end{array}$ & $0.01(3.3 \%)$ & $\begin{array}{l}0.009 \\
(3.2 \%)\end{array}$ & $\begin{array}{l}0.002 \\
(1.3 \%)\end{array}$ & ND \\
\hline$\beta-1^{\prime}$ (spirodienones, F) & $\begin{array}{l}0.016 \\
(4.6 \%)\end{array}$ & $\begin{array}{l}0.009 \\
(3.1 \%)\end{array}$ & $\begin{array}{l}0.006 \\
(2.1 \%)\end{array}$ & $\begin{array}{l}0.001 \\
(0.8 \%)\end{array}$ & ND \\
\hline $\begin{array}{l}\text { Condensation Degree } \\
\left(\beta-\beta^{\prime} / \beta-0-4^{\prime}\right)\end{array}$ & 0.285 & 0.203 & 0.160 & 0.073 & - \\
\hline
\end{tabular}

All integral data was relative to methoxyl.

${ }^{a}$ The percentages of lignin aromatic units $(\mathrm{S}, \mathrm{G}$ and $\mathrm{H})$ were shown in brackets

${ }^{\mathbf{b}}$ The percentages of lignin interunit linkages $(A, B, C, D, E$ and $F)$ were shown in brackets

ND: not detected 
Table 2. Structural Characteristics in the HSQC Spectra of the isolated LCC samples.

\begin{tabular}{|c|c|c|c|c|c|}
\hline & & & LCC & & \\
\hline & $\mathrm{Od}$ & $20 d$ & $30 d$ & $40 d$ & $50 d$ \\
\hline lignin aromatic units ${ }^{a}$ & & & & & \\
\hline$S$ & $\begin{array}{c}0.23 \\
(62.1 \%)\end{array}$ & $\begin{array}{c}0.142 \\
(51.7 \%)\end{array}$ & $\begin{array}{c}0.113 \\
(50.6 \%)\end{array}$ & $\begin{array}{c}0.062 \\
(50.0 \%)\end{array}$ & $\begin{array}{c}0.052 \\
(49.4 \%)\end{array}$ \\
\hline G & $\begin{array}{c}0.06 \\
(32.5 \%)\end{array}$ & $\begin{array}{c}0.058 \\
(42.6 \%)\end{array}$ & $\begin{array}{c}0.05 \\
(45.0 \%)\end{array}$ & $\begin{array}{c}0.027 \\
(44.1 \%)\end{array}$ & $\begin{array}{c}0.024 \\
(46.0 \%)\end{array}$ \\
\hline $\mathrm{H}$ & $\begin{array}{c}0.02 \\
(5.40 \%)\end{array}$ & $\begin{array}{c}0.015 \\
(5.60 \%)\end{array}$ & $\begin{array}{c}0.01 \\
(4.40 \%)\end{array}$ & $\begin{array}{c}0.007 \\
(5.90 \%)\end{array}$ & $\begin{array}{c}0.005 \\
(4.60 \%)\end{array}$ \\
\hline FA & 0.049 & 0.012 & 0.009 & 0.004 & 0.002 \\
\hline $\mathrm{FA} /(\mathrm{S}+\mathrm{G}+\mathrm{H})$ & $39.4 \%$ & $13.2 \%$ & $12.3 \%$ & $10.1 \%$ & $6.0 \%$ \\
\hline Lignin interunit linkages & & & & & \\
\hline $\begin{array}{l}\beta-0-4^{\prime} \text { aryl ethers } \\
\left(A / A^{\prime}\right)\end{array}$ & 0.234 & 0.222 & 0.213 & 0.209 & 0.198 \\
\hline$\beta-\beta^{\prime}($ resinols, $C)$ & 0.012 & ND & ND & ND & ND \\
\hline LCC interunit linkages & & & & & \\
\hline $\begin{array}{l}\text { Benzyl ether } \\
\text { (BE) }\end{array}$ & 0.004 & ND & ND & ND & ND \\
\hline $\begin{array}{l}\text { Phenyl glycoside } \\
\text { (PhyGlc) }\end{array}$ & 0.017 & 0.010 & 0.005 & 0.003 & 0.002 \\
\hline $\begin{array}{l}\text { Phenyl glycoside } \\
\text { (PhyGlc) }\end{array}$ & 0.008 & 0.004 & 0.003 & 0.003 & 0.003 \\
\hline $\begin{array}{l}\text { Y-ester linkages } \\
\left(A^{\prime} Y\right)\end{array}$ & 0.231 & 0.156 & 0.132 & 0.083 & 0.058 \\
\hline $\begin{array}{l}\text { esterified 4-0-methyl-a-D- } \\
\text { glucuronic acid } \\
\text { (GlcAE) }\end{array}$ & 0.015 & 0.005 & 0.005 & 0.002 & 0.002 \\
\hline
\end{tabular}

All integral data was relative to methoxyl.

a The percentages of lignin aromatic units $(\mathrm{S}+\mathrm{G}+\mathrm{H})$ were shown in brackets 


\section{Figures}

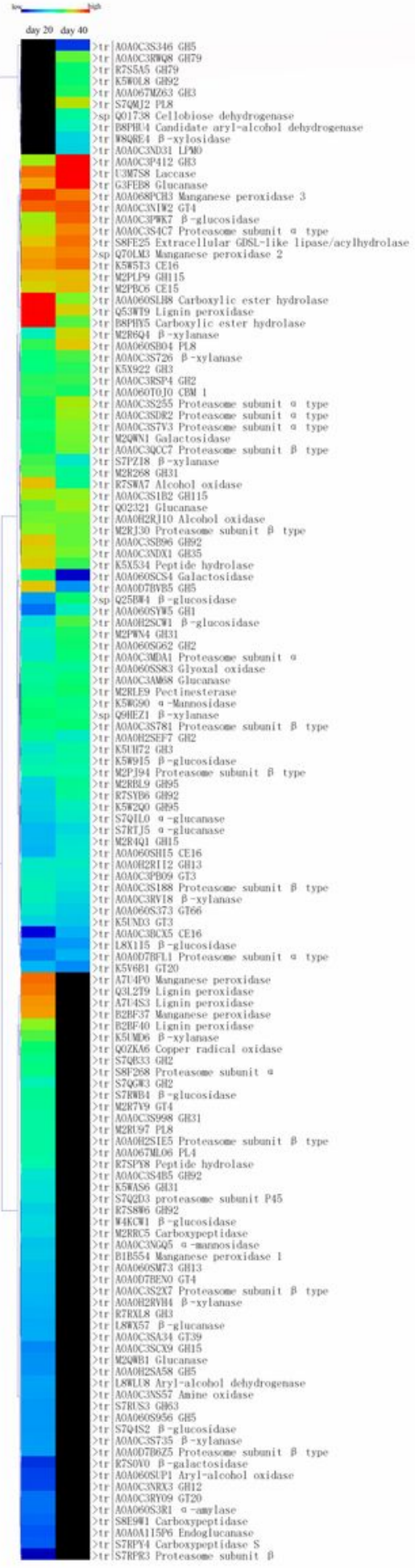

b

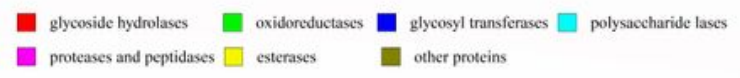

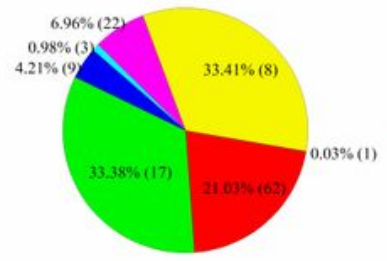

day 20

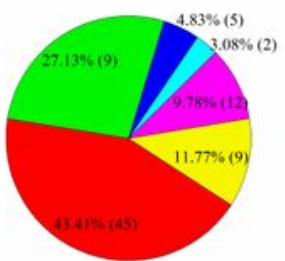

day 40

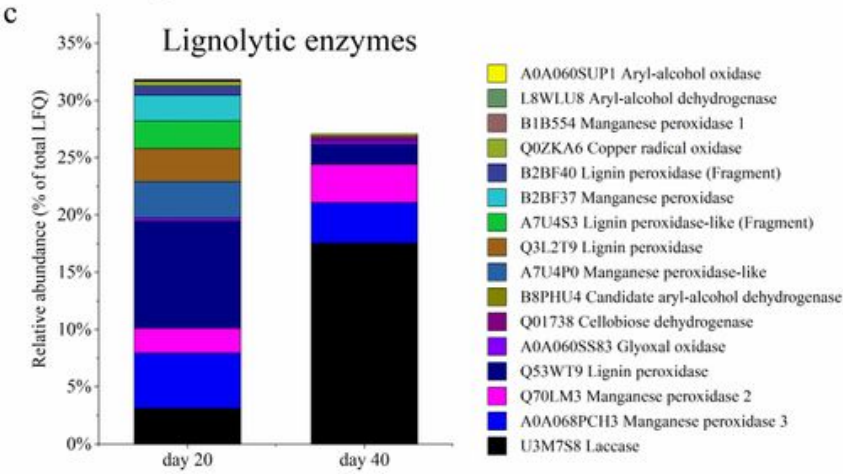

d
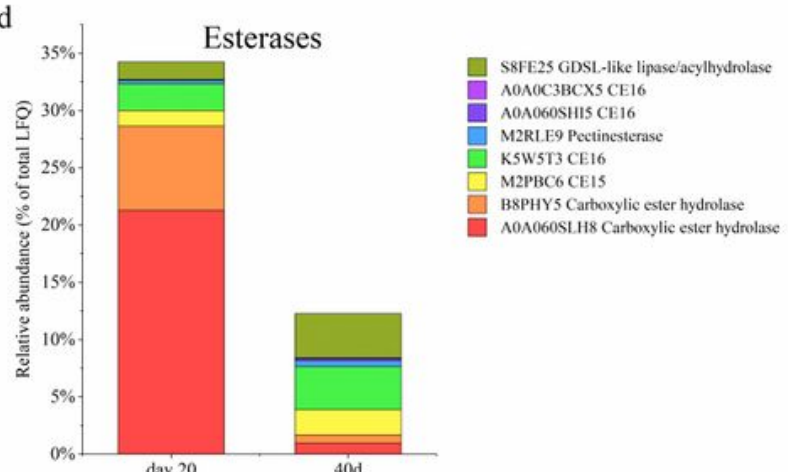

e

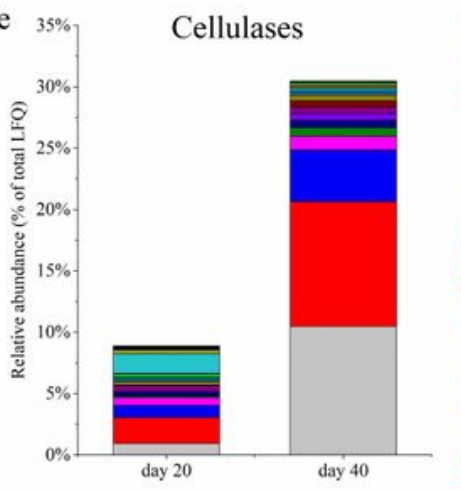

R7RX1.8 GH3

NOAOC 3 NRX3 GH12

A0A0A II5P6 Edoglucanase

A0A0H2SA 58 GHS

M2QWBI Glucanase
7Q4S2 endo-1,3,1,4- $\beta$-D-glucanase

A0A060S 956 GH5

W4KCW1 $\beta$-glucosidase

7RWB4 $\beta$-glucosida

N0A0C 35346 GHS

18X115 B-glucosidas

(2)

915 B-glucosida

K5UH 72 GH 3

3AM68 Glucanase

Q25BW 4 -glucosidas

$10 \mathrm{~A} 067 \mathrm{MZ63} \mathrm{GH} 3$

K5X922 GH 3

AOAOH2SCW1 B-glucosidas

Q0232I Glucanase

Figure 1 
Secretomic analysis of E. taxodii 2538 cultured on bamboo. (a) Expression of all secreted proteins at day 20 and day 40. Unexpressed proteins are colored as black. (b) Relative abundance of the main protein types in the secretomes at day 20 and day 40 . The number of expressed proteins is marked in brackets. (c)-(e) The relative abundance accounted for the total secreted proteins of extracellular ligninolytic enzymes, esterases, cellulases, respectively.
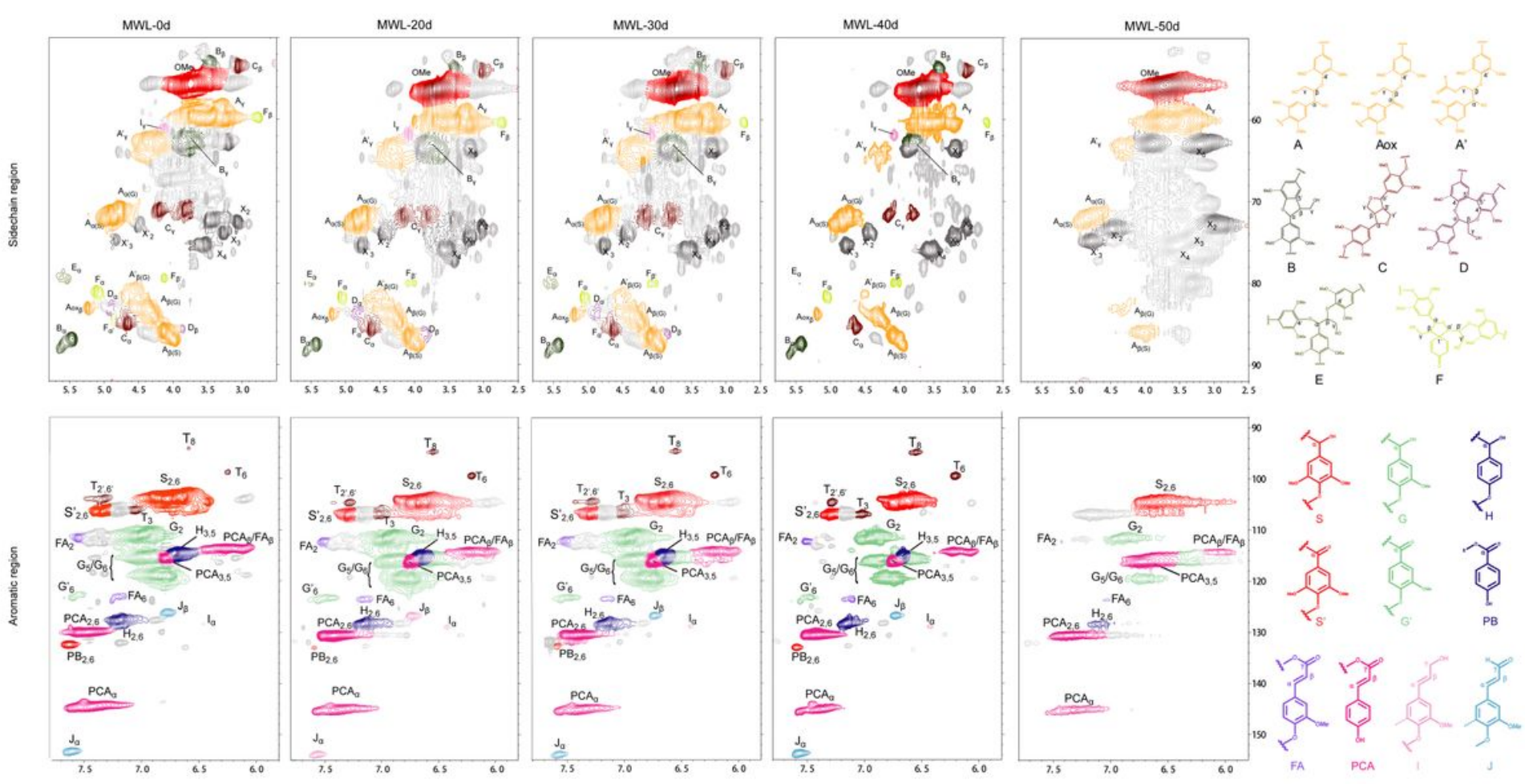

\section{Figure 2}

HSQC spectra of the isolated MWL samples from raw and treated bamboo. The up is the side chain $(\delta \mathrm{C} /$ $\delta \mathrm{H} 50-90 / 2.8-5.8)$ regions and the below is the aromatic $(\delta \mathrm{C} / \delta \mathrm{H} 90-155 / 5.8-7.8)$ regions. Main structures in the MWL preparations were shown at right side. 

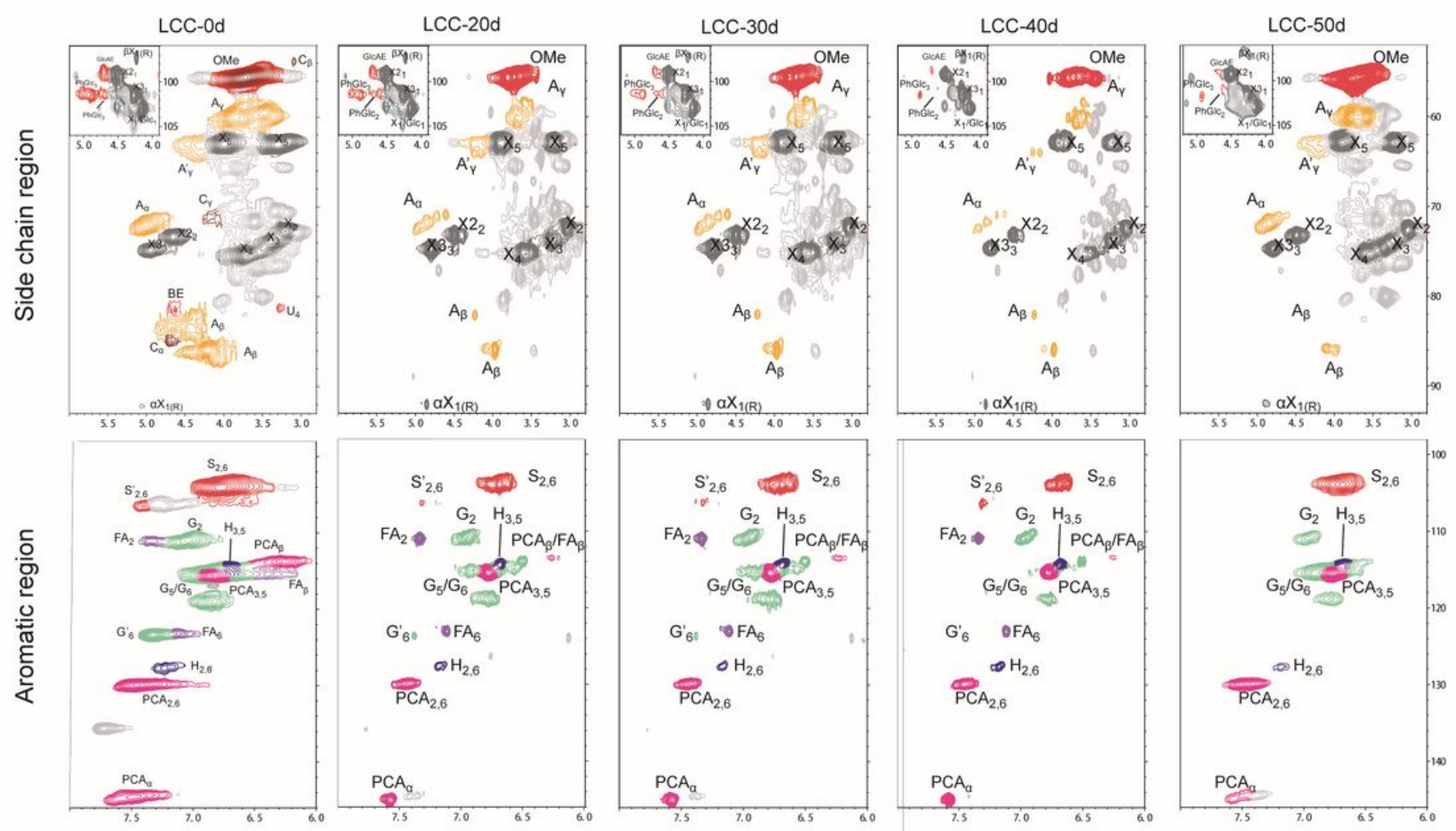

\section{Figure 3}

HSQC spectra of the isolated LCC samples from raw and treated bamboo. The up is the side chain regions and the below is the aromatic regions. Main linkages in the LCC preparations were shown in Figure 4.

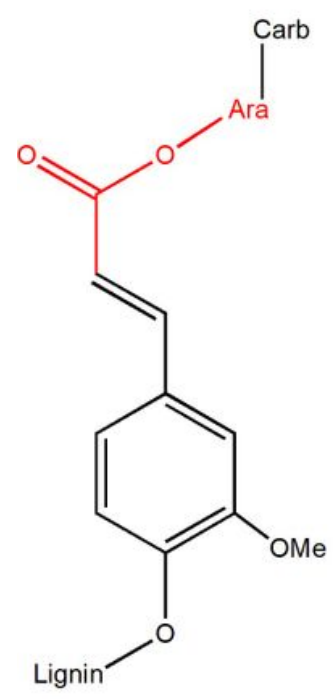

FA-ester linkages

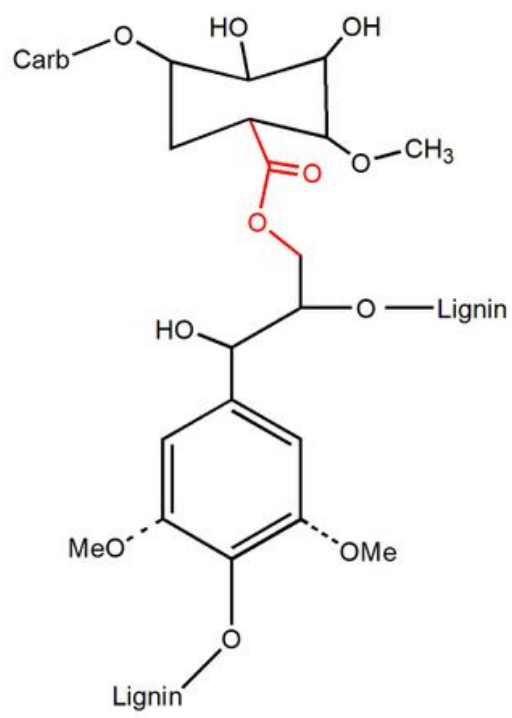

$\gamma$-esters

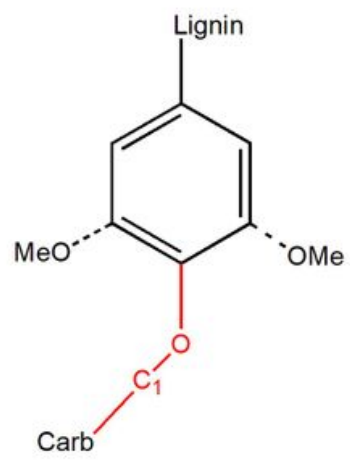

phenyl glycoside bonds

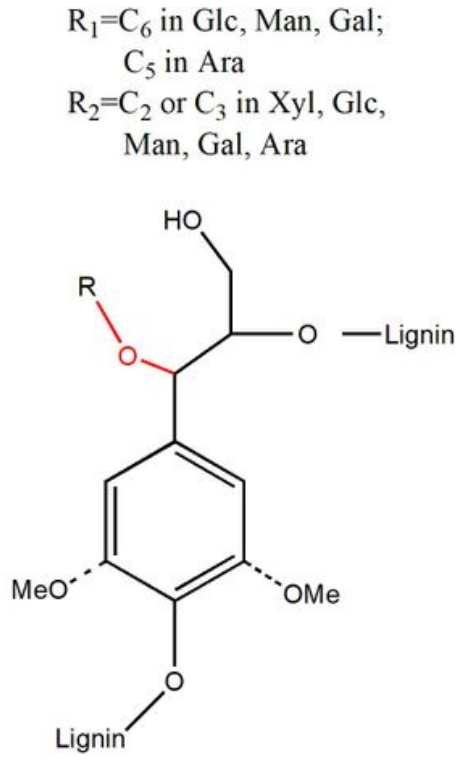

benzyl ethers

Figure 4

Main linkages identified in LCCs of bamboo. 